УДК622.271

\title{
ОЦЕНКА ВАРИАНТОВ ОТРАБОТКИ ПРИБОРТОВЫХ И ПОДКАРЬЕРНЫХ ЗАПАСОВ РУДНИКА «ОЛЕНИЙ РУЧЕЙ»
}

\author{
Немова Наталья Анатольевна', \\ nemova-nataly@mail.ru \\ Бельш Татьяна Александровна ${ }^{1}$, \\ tata0303@bk.ru \\ 1 Институт горного дела им. Н.А. Чинакала Сибирского отделения Российской академии наук,
Россия, 630091, г. Новосибирск, Красный проспект, 54.
}

\begin{abstract}
Актуальность исследования обусловлена необходимостью отработки новых рудных тел, появившихся в ходе проведения опережающей эксплуатационной разведки. За проектными контурами рудников остаются запасы, которые необходимо доработать либо подземным, либо комбинированным способами. При технологии доработки прикарьерных запасов возникают наибольшие сложности, поскольку их отработка вызывает нарушение обеспечения устойчивости откосов борта карьера. Поэтому поиск, выбор и определение главных параметров системы разработки прикарьерных запасов при доработке месторождений, обеспечивающих эффрективное и безопасное освоение запасов, представляет весьма актуальную задачу.

Цель: рассмотреть возможные варианты отработки прибортовых и подкарьерных запасов с учетом залегания новых рудных тел апатит-нефелинового месторождения и соблюдением необходимых условий для заданного направления развития горных работ в границах горного отвода и произвести технико-экономическую оценку предложенных вариантов.

Объект: крупное месторождение апатит нефелиновых руд «Олений ручей».

Методы: горно-геологический анализ верхнего яруса месторождения апатит-нефелиновых руд «Олений ручей» и анализ существующих данных о физико-механических свойствах горных пород, слагающих массив рассматриваемого месторождения, анализ возможных схем развития горных работ при отработке прикарьерных запасов с оценкой возможности внутреннего отвалообразования при доработке карьера.

На примере разработки месторождения апатит-нефелиновых руд «Олений ручей» авторами рассмотрены возможные варианты отработки и вскрытия прибортовых и подкарьерных запасов верхнего яруса месторождения с соблюдением условий развития горных работ в границах горного отвода. Предложено оптимальное развитие горных работ по варианту, предусматривающему минимальный коэфффициент вскрыши.
\end{abstract}

\section{Ключевые слова:}

Прибортовые и подкарьерные запасы, рудные тела, схемы вскрытия, доработка запасов, коэффрициент вскрыши, положения горных работ.

\section{Введение}

Поиск, выбор и обоснование вариантов разработки рудных тел, обнаруженных в ходе разведки, обеспечивающих безопасное и эффективное освоение месторождения, а также экономически целесообразное с наибольшей полнотой извлечения, является актуальной задачей в настоящее время.

В горно-добывающей области произведен наибольший объём исследований, но отсутствие нормативной базы и документов является большой проблемой для проектирования рациональных систем разработки и схем вскрытия прибортовых и подкарьерных запасов.

Отсутствуют методики выбора конструкции систем разработки прибортовых и подкарьерных запасов открытым, подземным или комбинированным способом, не обоснован рациональный порядок отработки таких запасов.

Анализ месторождений полезных ископаемых, отрабатываемых открытым способом, показал, что геологические запасы в бортах достигают 45 \% всех запасов, находящихся в прикарьерной зоне. Однако, как показывает опыт, не все горно-добывающие предприятия готовы отработать такие запасы, в связи с этим они вынуждены оставлять их, при этом увеличиваются потери полезного ископаемого. Но, с другой стороны, для повышения эффективности доосвоения, полноты извлечения рудных залежей, находящихся в подкарьерной и прибортовой зоне, и получения дополнительной прибыли необходимо найти эффективные технологические решения рациональной отработки этих запасов и технико-экономической оценки целесообразности выемки для различных участков залежи [1-5].

Эффективные технологические решения доработки законтурных запасов должны учитывать ряд условий:

- безопасность отработки рудных запасов;

- сохранность бортов карьера в устойчивом состоянии;

- минимальные показатели потерь и разубоживания руды.

Выемка законтурных запасов руды была успешно осуществлена на карьерах Гайского ГОКа, Сибайском, Учалинском, Бакальского рудоуправления и др. Например, на Сибайском месторождении после завершения открытых горных работ в карьере и постановки борта в предельное положение отработка прибортовых запасов осуществлялась подземным способом, а существующий съезд, расположенный на борту, использовался для доступа к штольням. Доработка Учалинского месторождения продолжается как открытым, так и подземным способами, где подкарьерные запасы были отработаны подземным способом [6-18]. 
Таким образом, объектом исследований являются прибортовые и подкарьерные запасы верхнего яруса месторождения «Олений ручей».

В связи с этим был произведен детальный анализ условий залегания запасов верхнего яруса месторождения «Олений ручей», по результатам которого предложены варианты доработки части прикарьерных запасов.

\section{Анализ горно-геологических условий залегания прибортовых и подкарьерных запасов верхнего яруса месторождения «Олений ручей»}

При проектировании технологии выемки прикарьерных запасов возникают наибольшие сложности изза снижения устойчивости откосов бортов и уступов карьера. Месторождение апатит-нефелиновых руд «Олений ручей» расположено в восточной части Хибинского горного массива в Кировском районе Мурманской области, в 22 км северо-восточнее города Кировск. Месторождение представлено несколькими рудными телами, вытянутыми в направлении с югозапада на северо-восток на 1,5 км. Его освоение возможно комбинированным открыто-подземным способом для большей полноты извлечения запасов апатит-нефелиновых руд [19-24].

В верхнем ярусе выделено шесть рудных тел (сверху вниз: 1B, 2B, 3В, 4В, 5B и 6В), имеющих лин- зообразную форму, сложную морфологию и изменчивое качество руды, по падению они прослеживаются на абсолютных отметках от -115 до +450 м (рис. 1).

Мощность подкарьерных и прибортовых рудных тел изменяется от 2,0-9,0 до 25,0-65,0 м.

Результаты анализа горно-геологических условий залегания и размеров рудных тел верхнего яруса, располагающихся в рассматриваемых подкарьерной и прибортовой зонах, сведены в табл. 1.

Таблица 1. Размеры рудных тел верхнего яруса

Table 1. Dimensions of ore bodies of the upper tier

\begin{tabular}{|l|c|c|c|c|c|c|c|}
\hline $\begin{array}{l}\text { Наименование } \\
\text { Designation }\end{array}$ & \multicolumn{7}{|c|}{ Рудные тела/Ore bodies } \\
\cline { 2 - 8 } & 1В & 2В & 2B-1 & 3В & 4В & 5В & $6 \mathrm{~B}$ \\
\hline $\begin{array}{l}\text { Прослежено по прости- } \\
\text { pанию, м Traced along } \\
\text { the strike, } \mathrm{m}\end{array}$ & 280 & 1120 & 280 & 560 & 740 & 560 & 320 \\
\hline $\begin{array}{l}\text { Прослежено по падению } \\
\text { до горизонта } \\
\begin{array}{l}\text { Traced by the fall to the } \\
\text { horizon }\end{array}\end{array}$ & +180 & -115 & +80 & +50 & +85 & +195 & +205 \\
\hline $\begin{array}{l}\text { Прослежено по восста- } \\
\text { нию до горизонта } \\
\text { Traced from the rebellion } \\
\text { to the horizon }\end{array}$ & +360 & +420 & +235 & +315 & +420 & +390 & +370 \\
\hline $\begin{array}{l}\text { Средняя мощность } \\
\text { (истин.), м } \\
\text { Аverage роwer (true), } \mathrm{m}\end{array}$ & 10,85 & 13,58 & 17,97 & 10,07 & 12,81 & 14,4 & 10,51 \\
\hline
\end{tabular}

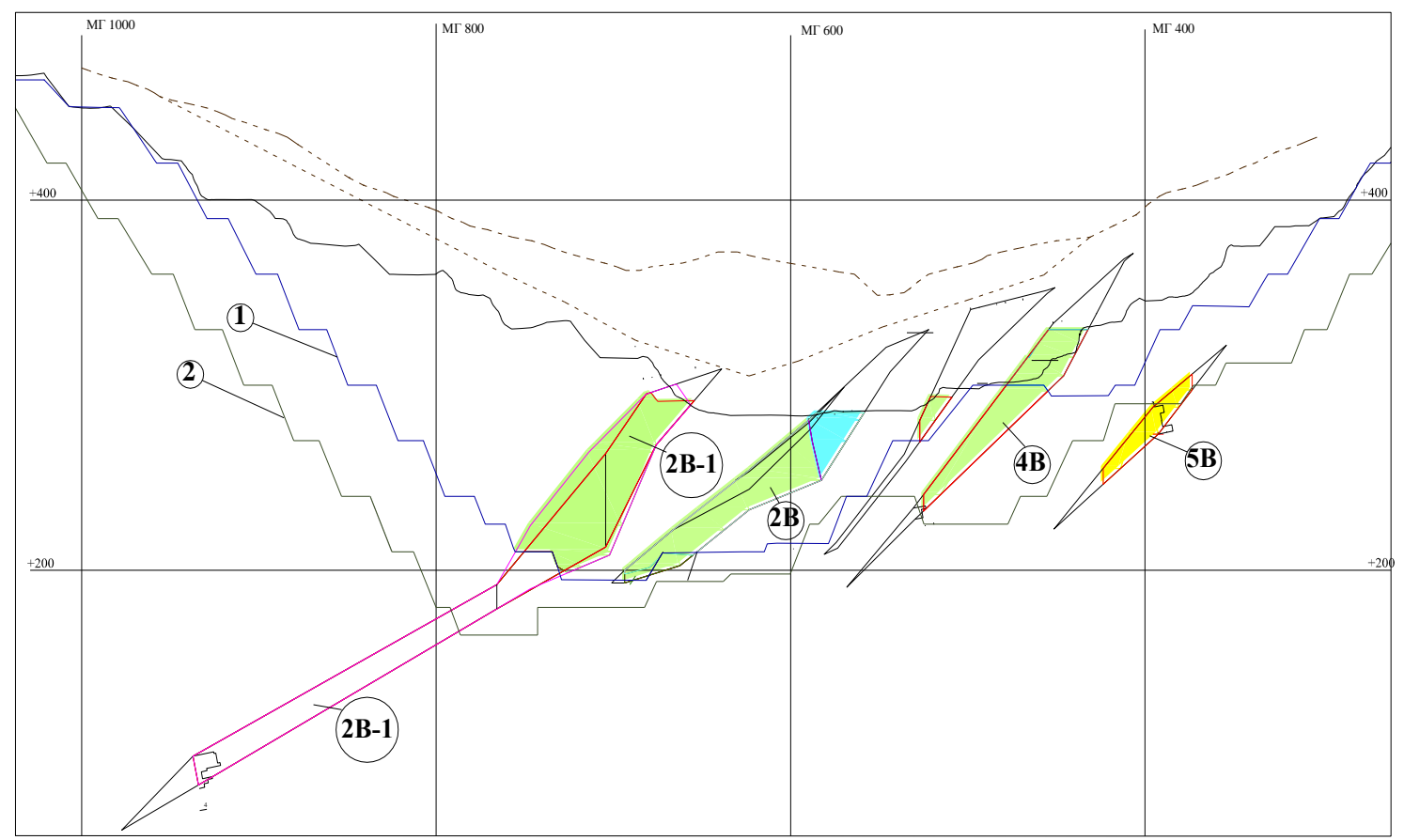

Pис. 1. Рудные тела 2B, 4B, 5B, 2B-1 подкарьерного и прибортового контура верхнего яруса месторождения «Олений ручей»: 1) проектный контур карьера; 2) контур карьера по варианту 3

Fig. 1. Ore bodies $2 B, 4 B, 5 B, 2 B-1$ of the pit bottom and pit wall contour of the upper tier of the deposit «Oleniy Ruchey»: 1) design contour of the quarry; 2) contour of the quarry according to option 3

\section{Метод исследования}

При проведении эксплуатационной разведки на поле верхнего яруса месторождения «Олений ручей» за пределами контура технических границ карьера в подкарьерной и прибортовой (в лежачем боку рудной за- лежи) зонах выявлены и прослежены рудные тела 1B, 2B, 2B-1, 3В, 4В, 5В и 6В. Эти рудные тела разделены вмещающими породами мощностью 10-70 м, либо целиком локализуются за пределами технических границ на определенном удалении от них, которое состав- 
ляет от 6-18 до 28-200 м, либо залегают так, что часть рудного тела располагается в проектном контуре карьера, а часть - за его пределами, что чаще всего наблюдается в подкарьерной зоне [7, 19-22].

Проведен подробный горно-геометрический анализ верхнего яруса месторождения. При выполнении анализа методом параллельных сечений произведен подсчет объемов руды и вскрышной породы за пределами проектного контура карьера. Сущность метода заключается в разбиении месторождения вертикальными сечениями (разрезами), расстояние между которыми составляет от 20 до 80 м. Для подсчета запасов залежь полезного ископаемого разделяется на отдельные блоки, границами которых являются профильные сечения. Результаты расчета представлены в табл. 2.

Таблица 2. Распределение подкарьерных и прибортовых запасов руды по профильным линиям

Table 2. Distribution of pit bottom and pit wall ore reserves for profile lines

\begin{tabular}{|c|c|c|c|c|c|c|}
\hline \multirow{4}{*}{ 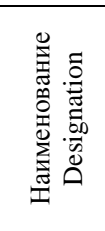 } & \multicolumn{6}{|c|}{ Объёмы руды/Ore volumes } \\
\hline & \multirow{2}{*}{ 总 풍 } & \multicolumn{2}{|c|}{$\begin{array}{l}\text { в том числе } \\
\text { including }\end{array}$} & \multirow{2}{*}{ 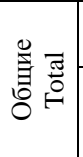 } & \multicolumn{2}{|c|}{$\begin{array}{c}\text { в том числе } \\
\text { including }\end{array}$} \\
\hline & & $\begin{array}{l}\text { подкарь- } \\
\text { ерные } \\
\text { pit bottom }\end{array}$ & $\begin{array}{l}\text { прибор- } \\
\text { товые } \\
\text { pit wall }\end{array}$ & & $\begin{array}{c}\text { подкарь- } \\
\text { ерные } \\
\text { pit bottom }\end{array}$ & $\begin{array}{l}\text { прибор- } \\
\text { товые } \\
\text { pit wall }\end{array}$ \\
\hline & \multicolumn{3}{|c|}{ тыс. $\mathrm{m}^{3} /$ thousand $\mathrm{m}^{3}$} & \multicolumn{3}{|c|}{ тыс. т/thousand tons } \\
\hline $\begin{array}{l}\text { Про- } \\
\text { фильные } \\
\text { линии } \\
18 . . .42 \\
\text { Profile } \\
\text { lines } \\
18 . . .42\end{array}$ & 3840 & 2756 & 1084 & 11520 & 8268 & 3252 \\
\hline
\end{tabular}

Анализ возможных схем развития горных работ с оценкой возможности внутреннего отвалообразования при доработке карьера

Исследованы возможные схемы развития горных работ при отработке прибортовых и подкарьерных запасов.

В результате анализа выявлено, что рудные тела в подкарьерной зоне по падению простираются вплоть до горизонта -115 м, по восстанию - до горизонта $+435 \mathrm{M}$

Рассмотрены три варианта возможных схем вскрытия и доработки подкарьерных и прибортовых запасов верхнего яруса месторождения с соблюдением условий развития горных работ в границах горного отвода и предложены новые положения горных работ, отличающиеся от проектного [7, 19-22]:

Вариант 1 предусматривает максимально возможное вовлечение в отработку прибортовых и подкарьерных запасов в существующих границах горного отвода карьера из условия обеспечения заезда с поверхности на самый нижний горизонт.

В результате исследований выявлено, что открытыми горными работами в подкарьерную зону возможно спуститься максимально только до горизонта +120 м в северо-восточной части месторождения и до горизонта +150 м в юго-западной части месторождения, а также максимально вовлечь в отработку запасы руды в прибортовой части.
Всего по рассматриваемому варианту в отработку вовлекаются 1710 тыс. м ${ }^{3}$ руды (табл. 3). Из них прибортовых запасов руды, прослеженных в лежачем боку рудной залежи (под восточным бортом рудника), в рассматриваемом варианте в отработку вовлекаются 788 тыс. м ${ }^{3}$, и объем вовлекаемых в отработку подка-

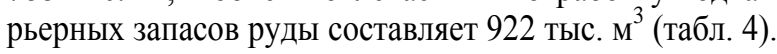

Таким образом, общий объем запасов руды в прибортовой зоне, который не представляется возможным отработать открытым способом при неизменном положении восточного участка границы горного отвода карьера, составляет 296 тыс. м $^{3}$.

Для обеспечения добычи руды потребуется извлечь 29650 тыс. м ${ }^{3}$ вскрышных пород, в том числе уборка старых навалов - 1550 тыс.м³. Однако значение коэффициента вскрыши в этом случае составляет $17,3 \mathrm{~m}^{3} / \mathrm{m}^{3}$, что значительно превышает значение граничного коэффициента вскрыши, определяющегося из условия равенства себестоимости отработки руды подземным и открытым способами, $12 \mathrm{~m}^{3} / \mathrm{m}^{3}$. При этом весь объем вынимаемых вскрышных пород должен быть вывезен и уложен во внешние отвалы.

Вариант 2 предусматривает максимально возможное, как в варианте 1, вовлечение в отработку прибортовых запасов и части подкарьерных запасов рудных тел, прослеженных эксплуатационной разведкой в юго-западной части поля рудника с углубкой проектных границ на 15-45 м.

Анализируя результаты построений и расчетов, произведенных по варианту 1, при максимально возможной углубке карьера, в варианте 2 предлагается:

- как и в предыдущем варианте, максимально возможно забрать открытым способом прибортовые запасы руды, прослеженные в лежачем боку рудной залежи (под восточным бортом рудника);

- из подкарьерных запасов в отработку вовлечь только рудные тела 6В и часть 2В с углубкой проектных границ в указанной части поля рудника на 15-45 м (с горизонта +210 до горизонта + 195 м);

- в северо-восточной части поля рудника его техническая граница по дну и по западному борту остается не измененной.

В рассматриваемом варианте схемы вскрытия общий объем запасов руды, вовлекаемых в отработку, составляет 880 тыс. м', из которых 788 тыс. м³ составляют прибортовые запасы и 92 тыс. м ${ }^{3}-$ подкарьерные (табл. 3, 4).

Для обеспечения такого объема добычи руды по варианту 2 потребуется извлечь 7800 тыс. м $^{3}$ вскрышных пород. Значение коэффициента вскрыши в варианте составляет $8,9 \mathrm{~m}^{3} / \mathrm{m}^{3}$ (табл. 3).

Ввиду того, что отработку подкарьерных запасов после окончания открытых горных работ предусматривается осуществлять подземным способом с применением системы разработки с обрушением кровли, в донной части карьерной выемки предварительно необходимо отсыпать слой из вскрышных пород мощностью как минимум до 20 м - так называемую породную подушку. 
В рассматриваемом варианте схемы вскрытия весь объем вынимаемой породы вскрыши представляется возможным уложить во внутренний отвал в северовосточной части поля рудника, при этом углубка в торце и в донной части выработанного до проектного контура пространства рудника не предусматривается.

Вариант 3. Отработка прибортовых запасов осуществляется так же, как в вариантах 1, 2. Подкарьерные запасы руды в юго-западной части поля рудника вскрывается так же, как в варианте 2, а в северовосточной части производится углубка карьера и вовлекаются в отработку подкарьерные запасы руд до горизонта +135 м [7, 8].

В предлагаемом варианте рассматривается отработка прибортовых запасов руды и части подкарьерных запасов в юго-западной части поля рудника так же, как и в варианте 2, а в северо-восточной части рудника отработка подкарьерных запасов осуществляется с углубкой до горизонта +135 м (рис. 2).

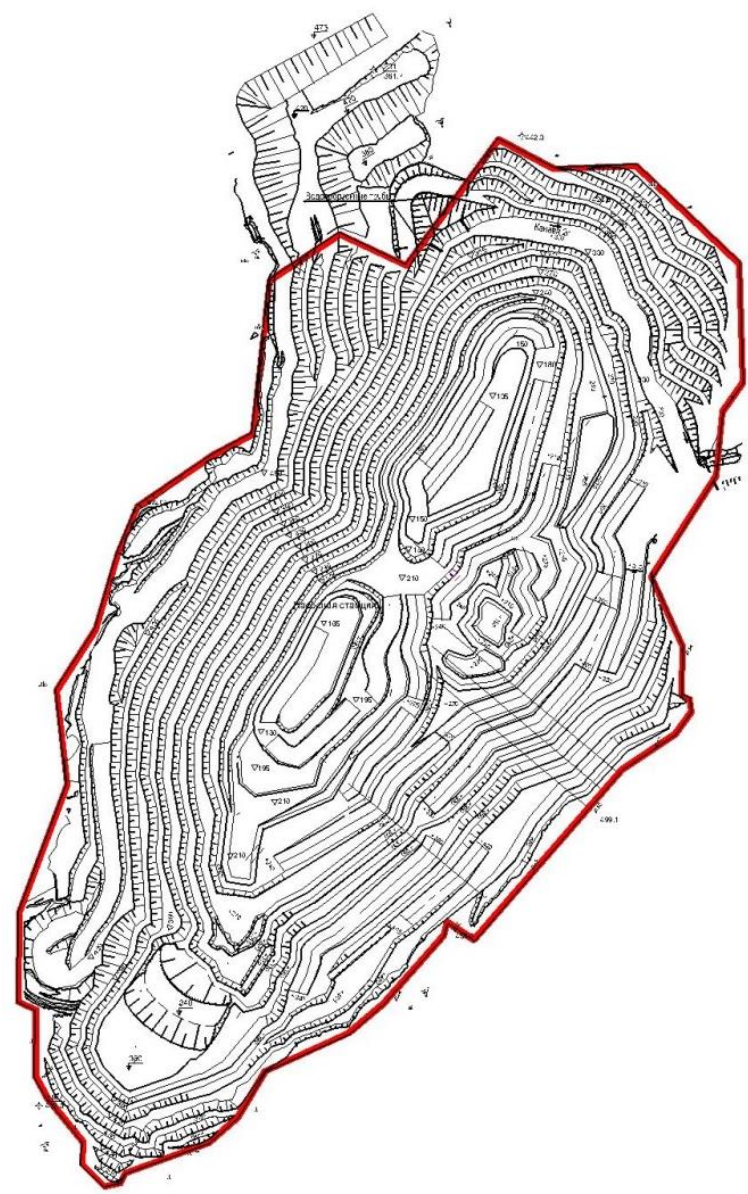

Pис. 2. Положение горных работ на конеи отработки опытно-промышленного участка по Варианту 3

Fig. 2. Position of mining operations at the end of development of the pilot industrial site for Option 3

Как показали результаты горно-геометрического анализа и расчеты вынимаемых объемов полезного ископаемого (руды) и вскрышных пород, схема вскрытия и подготовки прибортовых и подкарьерных запасов по предлагаемому варианту является наибо- лее рациональной по сравнению с предыдущими двумя вариантами.

Общий объем руды, вовлекаемый в отработку по рассматриваемому варианту, составляет 1039 тыс. м ${ }^{3}$ (табл. 3). В том числе 788 тыс. м ${ }^{3}$ составляют прибортовые запасы и 251 тыс. м ${ }^{3}$ - подкарьерные (табл. 4).

Общий объем вскрышных пород, извлекаемых при этом, составит 8550 тыс. м³ . Геологический коэффициент вскрыши по варианту равен $8,2 \mathrm{~m}^{3} / \mathrm{m}^{3}$ при значении граничного $12 \mathrm{~m}^{3} / \mathrm{m}^{3}$, что меньше не только по сравнению с результатом, полученным в Варианте 1, но и по сравнению с результатом, полученным в $B a$ рианте 2 .

Вынимаемые породы вскрыши в рассматриваемом варианте предусматривается уложить частично в выработанном пространстве с закладкой его южного и северного торцов до горизонта +240 и частично на внешний отвал.

Таблица 3. Объёмы вынимаемой руды и вскрыши по вариантам

Table 3. Volumes of removable ore and overburden by options

\begin{tabular}{|c|c|c|c|c|}
\hline $\begin{array}{r}\text { Наименование } \\
\text { Designation }\end{array}$ & 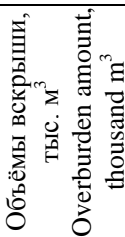 & 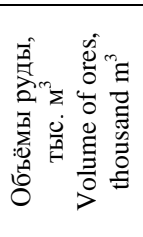 & 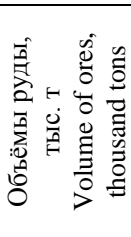 & 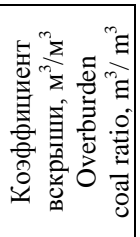 \\
\hline 1 & 29650 & 1710 & 5130 & 17,3 \\
\hline 2 & 7800 & 880 & 2640 & 8,9 \\
\hline 3 & 8550 & 1039 & 3117 & 8,2 \\
\hline
\end{tabular}

Таблица 4. Распределение отрабатываемых по вариантам запасов руды на подкарьерные и прибортовые

Table 4. Distribution of ore reserves worked out by the options over pit wall and pit bottom

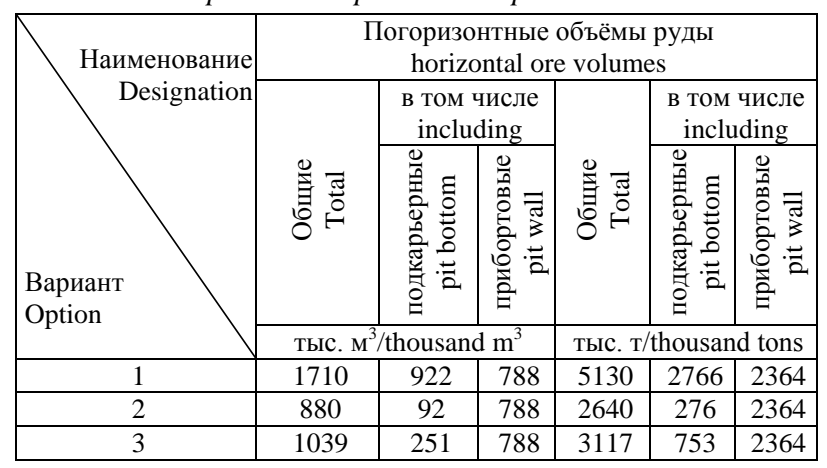

\section{Обоснование рациональной схемы вскрытия и подготовки прибортовых и подкарьерных запасов месторождения «Олений ручей»}

По итогам анализа трех рассмотренных возможных вариантов схем вскрытия и подготовки прибортовых и подкарьерных запасов руды на месторождении «Олений ручей» можно сделать вывод, что наиболее рациональной является схема вскрытия в Варианте 3. Этот вариант и предлагается к реализации [22]. 
При разработке технологических решений отработки прибортовых и подкарьерных запасов с учетом геомеханической обстановки месторождения «Олений ручей» и рассмотрении возможных вариантов были приняты проектные углы наклоны уступа и проектные углы откоса бортов, т. е. результирующий угол откоса висячего борта принят $48^{\circ}$, а лежачего $44^{\circ}$.

По условиям рельефа местности карьерное поле делится на нагорную часть до отметки 315 м и глубинную часть ниже отметки 315 м.

Нагорные горизонты северо-западного борта карьера, согласно решениям, принятым при реализации Варианта 3, также намечается вскрывать полутраншеями с соответствующих отметок автодороги, связывающей карьер с отвалом № 1.

Глубинную часть опытно-промышленного участка (ниже горизонта +315 м), так же как и по факту в действующем карьере, предлагается вскрывать со стороны северо-восточного торца системой постоянных съездов.

Связь с промплощадкой рудника также будет осуществляться автодорогой, располагающейся с северо-восточной стороны карьера.

Рекомендации по выбору систем разработки при отработке прибортовых и подкарьерных запасов

Учитывая тот факт, что горно-геологические условия в пределах технических границ верхнего яруса рассматриваемого месторождения «Олений ручей» не изменяются по глубине и по простиранию, для отработки прибортовых запасов, как и при отработке запасов в технических границах карьера, принимается следующая система разработки месторождения:

- по степени зависимости вскрышных, добычных и горно-подготовительных работ - зависимая;

- по направлению подвигания фронта горных работ в плане - продольная;

- по направлению выемки в плане - углубочная однобортовая;

- по направлению перемещения вскрышных пород в отвал - транспортная, с продольным перемещением вскрышных пород во внешний и внутренний отвалы [22].

\section{Порядок отработки запасов, находящихся в прикарь- ерной зоне}

Установлено, что отработку запасов, находящихся в прикарьерной зоне в границах опытнопромышленного участка с учетом горногеологических условий месторождения «Олений ручей», рационально производить в следующем порядке:

На первом этапе произвести отработку максимально возможного объема прибортовых и подкарьерных запасов с углубкой карьера (по сравнению с проектным контуром) на 15 м в его северо-восточной части. Продолжительность этого этапа составит два года эксплуатации карьера. Параллельно с отработкой прибортовых подкарьерных запасов необходимо строить шахты для отработки подкарьерных запасов.
На втором этапе, после завершения работ в верхнем ярусе опытно-промышленного участка карьера, в эксплуатацию сдается шахта и осуществляется отработка подкарьерных запасов подземным способом [22].

\section{Основные технико-экономические показатели}

Основные технико-экономические показатели по геотехнологии отработки подкарьерных и прибортовых запасов верхнего яруса месторождения «Олений ручей» по принятому варианту приводятся в табл. 5 [22].

Таблица 5. Технико-экономические показатели

Table 5. Mining results

\begin{tabular}{|c|c|}
\hline $\begin{array}{l}\text { Наименование } \\
\text { Name }\end{array}$ & $\begin{array}{c}\text { Показатели } \\
\text { Indicators }\end{array}$ \\
\hline $\begin{array}{l}\text { Балансовые запасы для открытой отработки, тыс. т. } \\
\text { Balance reserves for open mining, thousand tons }\end{array}$ & 3117,0 \\
\hline Потери руды, \%/Ore loss, \% & 3,03 \\
\hline Разубоживание руды, \%/Ore contamination, \% & 6,97 \\
\hline $\begin{array}{l}\text { Эксплуатационные запасы (добыча), тыс. т } \\
\text { Mineable reserves (mining), thousand tons }\end{array}$ & 3159,0 \\
\hline $\begin{array}{l}\text { Годовая производственная мощность, тыс. т/год } \\
\text { Annual capacity, thousand tons/year }\end{array}$ & 1881,0 \\
\hline $\begin{array}{l}\text { Количество добытой руды, тыс. т/тыс. }{ }^{3} \\
\text { Quantity of ore mined, thousand tons/thousand } \mathrm{m}^{3}\end{array}$ & $3159 / 1053$ \\
\hline Вскрыша, тыс. $\mathrm{m}^{3} /$ Overburden, thousand $\mathrm{m}^{3}$ & 8550 \\
\hline Горная масса, тыс. $\mathrm{m}^{3} /$ Mined rock, thousand $\mathrm{m}^{3}$ & 9603 \\
\hline $\begin{array}{l}\text { Стоимость товарной продукции, млн р. } \\
\text { Amount of saleable output, million rubles }\end{array}$ & 5708,4 \\
\hline $\begin{array}{l}\text { Цена реализации апатитового концентрата } \\
\text { (без НДС), p./т } \\
\text { Selling price of apatite concentrate (without VAT), } \\
\text { rub./t }\end{array}$ & 6903,0 \\
\hline $\begin{array}{l}\text { Эксплуатационные расходы на производство } \\
\text { товарной продукции, млн р., всего } \\
\text { Operating costs for production of commercial } \\
\text { products, million rubles, total }\end{array}$ & 4244,3 \\
\hline \multicolumn{2}{|l|}{ в том числе/including: } \\
\hline добыча руды/ore mining & 3220,0 \\
\hline обогащение/benefication & 832,4 \\
\hline коммерческие расходы/business expenses & 191,9 \\
\hline \multicolumn{2}{|l|}{ Себестоимость единицы, p./т/Unit cost, rubles/t: } \\
\hline товарной продукции/marketable mineral products & 5132 \\
\hline $\begin{array}{l}\text { добычи руды (производственной) } \\
\text { ore mining (working) }\end{array}$ & 713 \\
\hline $\begin{array}{l}\text { то же, } \mathrm{p} / 1 \mathrm{~m}^{3} \text { горной массы } \\
\text { the same, rubles } / \mathrm{m}^{3} \text { mined rock }\end{array}$ & 235 \\
\hline $\begin{array}{l}\text { добычи руды (полной с учетом административ- } \\
\text { но-хозяйственных расходов) } \\
\text { ore mining (full taking into account administrative } \\
\text { expenses) }\end{array}$ & 1019 \\
\hline $\begin{array}{l}\text { то же, } \mathrm{p} / 1 \mathrm{~m}^{3} \text { горной массы } \\
\text { the same, rubles } / \mathrm{m}^{3} \text { mined rock }\end{array}$ & 335 \\
\hline
\end{tabular}

\section{Выводы}

Рассмотрены варианты доработки подкарьерных и прибортовых запасов верхнего яруса месторождения «Олений ручей» с соблюдением условий развития горных работ в границах горного отвода и предложены новые положения горных работ, отличающиеся от проектного.

Выполненный горно-геометрический анализ рассмотренных вариантов показал, что в первом варианте коэффициент вскрыши, равный $17 \mathrm{~m}^{3} / \mathrm{m}^{3}$, превыша- 
ет значение граничного, определяющегося из условия равенства себестоимости отработки руды подземным и открытым способами. При сравнении Варианта 2 и Варианта 3 более приемлемым оказался Вариант 3, т. к. коэффициент вскрыши меньше по сравнению с результатом, полученным в Варианте 2.

Предложенные положения горных работ для рассмотренных вариантов позволяют определить рациональную схему вскрытия прикарьерных запасов верхнего яруса месторождения «Олений ручей» для выбранного варианта.

Рассчитаны технико-экономические показатели по выбранному варианту доработки подкарьерных и прибортовых запасов верхнего яруса месторождения «Олений ручей» и приведены основные финансовые

\section{СПИСОК ЛИТЕРАТУРЬ}

1. Гавришев С.Е., Кузнецова Т.С., Некерова Т.В. Методика обоснования параметров бортов карьеров при выемке прибортовых запасов подземным способом // Вестник Магнитогорского государственного технического университета им. Г.И. Носова. - 2010. - № 1. - С. 14-17.

2. Калмыков В.Н., Григорьев В.В., Волков П.В. Изыскание вариантов систем разработки для выемки прибортовых запасов при комбинированной геотехнолгии // Вестник Магнитогорского государственного технического университета им Г.И. Носова. - 2010. - № 1. - С. 17-20.

3. Совершенствование систем разработки глубоких залежей на основе оптимизации элементов их вскрытия и параметров карьеров / Г.Г. Саканцев, М.Г. Саканцев, В.И. Ческидов, В.К. Норри // Физико-технические проблемы разработки полезных ископаемых. - 2014. - № 4. - С. 117-123.

4. Повышение эффективности технологий открытой разработки месторождений твердых полезных ископаемых / В.И. Ческидов, В.К. Норри, Г.Д. Зайцев, А.А. Ботвинник, А.С. Бобыльский, А.В. Резник // Физико-технические проблемы разработки полезных ископаемых. - 2014. - № 5. - С. 107-123.

5. Еремин Г.М. Повышение эффективности отработки Ньоркпахского месторождения открытым способом // Горный информационно-аналитический бюллетень (Научно-технический журнал). - 2012. - № 4. - С. 36-42.

6. Беляев С.И., Еремин Г.М. Повышение полноты отработки рудных тел Ньоркпахского месторождения при применении более крутого выпуклого борта карьера // Горный информационно-аналитический бюллетень (Научно-технический журнал). - 2004. - № 5. - С. 238-242.

7. Лобанов Е.А., Чайкин Д.А., Меньшиков П.Ю. Разработка технологических решений вскрытия и отработки прибортовых и подкарьерных запасов апатито-нефелиновых руд // Фундаментальные и прикладные науки в горном деле. 2018. - T. 5. - № 1. - C. 88-93.

8. Окунович А.В., Рыжков А.Н. О важности своевременного принятия решений по выбору оптимального варианта отработки запасов (на примере Ньоркпахского месторождения апатит-нефелиновых руд) // Горный журнал. - 2010. - № 4. С. $98-100$.

9. Калюжный А.С. Определение параметров нарушенной зонь и объёмов потенциальных вывалов для условий карьера «Олений ручей» // Горный информационно-аналитический бюллетень. - 2016. - № 7. - С. 403-412.

10. Dowling J., Beale G., Bloom J. Designing a large scale pit slope depressurization system at Bingham canyon // Annual International Mine Water Association Annual Conference. Reliable Mine Water Technology. - Denver, Colorado, USA 2013. - V. I. - P. 119-125.

11. Risk evaluation of slope failure at the Chuquicamata mine / A. Tapia, L.F. Contreras, M. Jefferies, O. Steffen // Slope Stability 2007. Proc. of 2007 International Symposium on Rock Slope Stability in Open Pit Mining and Civil Engineering / Ed. by Y. Potvin. - Perth, Australian Centre for Geomechanics, 2007. P. 477-495. результаты производственной деятельности рудника в границах опытно-промышленного, которые имеют высокие положительные значения:

- чистая прибыль за рассматриваемый период отработки (2 года) составляет 1160,7 млн р. (в каждом году периода оценки предприятие имеет чистую прибыль, что свидетельствует о финансовой состоятельности);

- чистый дисконтированный бюджетный доход государства за период оценки составляет 1039,3 млн р.;

- для отработки прибортовых и подкарьерных запасов верхнего яруса месторождения «Олений ручей» открытым способом не требуется привлечения дополнительных капитальных вложений.

12. The Transition from open pit to underground mining: An Unusual Slope Failure Mechanism at Palabora / R.K. Brummer, H. Li, A. Moss, T. Casten // Proc. of international symposium on stability of rock slopes in open pit mining and civil engineering. Johannesburg: The South African Institute of Mining and Metallurgy, 2006. - P. 411-420.

13. Wines D.R., Lilly P.A. Measurement and analysis of rock mass discontinuity spacing and frequency in part of the Fimiston open pit operation in Kalgoorie, Western Australia: a case study // International Journal of Rock Mechanics \& Mining Science. 2002. - V. 39. - № 5. - P. 589-602.

14. Руководство по проектированию бортов карьера / под ред. Д. Рид, П. Стейси / Пер с англ. - Екатеринбург: Правовед, 2015. $-544 \mathrm{c}$.

15. Laubcher D.H. A geomechanics classification system for rating of rock mass in mine design // Journal South Africa Inst. of Mining and Metallurgy. - 1990. - № 10. - P. 257-273.

16. Jacubec J., Laubcher D.H. The MRMR (Mining Rock Mass Rating) rock mass rating classification system in mining practice // Proc. of MassMin 2000. - Brisbane, Australia, 2000. - P. 413-421.

17. Laubcher D.H., Jacubec J. The MRMR (Mining Rock Mass Rating) rock mass classification for jointed rock masses // Underground Mining Methods: Engineering Fundamentals and International Case Studies. - Littleton, Colorado, USA: Society for Mining, Metallurgy, and Exploration (SME), 2000. - P. 475481 .

18. Haines A., Terbrugge P.J., Wittke W. Preliminary estimation of rock slope stability using rock mass classification systems // Proc. $7^{\text {th }}$ Cong. on Rock Mechanics 2. ISRM. - Aachen, Germany; Balkema, Rotterdam, 1991. - P. 887-892.

19. Отчет о научно-исследовательской работе «Инженерногеологические условия разработки апатитонефелинового месторождения Олений ручей». - Апатиты: Горный институт Кольского научного центра Российской академии наук, 2009. $-160 \mathrm{c}$.

20. Отчет о научно-исследовательской работе «Регламент на укручение бортов карьера месторождения апатитнефелиновой руды Олений ручей». - Апатиты: Горный институт Кольского научного центра Российской академии наук, 2012. -175 c.

21. Отчет о научно-исследовательской работе «Определение основных параметров физико-механических свойств горных пород по разрезу структурной инженерно-геологической скважины для оценки геомеханических условий проходки главного ствола». - Апатиты: Горный институт Кольского научного центра Российской академии наук, 2013. - 142 c.

22. Отчет о научно-исследовательской работе «Разработка основных технологических решений (регламента) для вскрытия и отработки прибортовых и подкарьерных запасов верхнего яруса месторождения Олений ручей». - Новосибирск: Институт горного дела Сибирское отделение Российской академии наук (ИГД СО РАН), 2018. - 180 с.

23. Козырев А.А., Семенова И.Э., Журавлева О.Г. Влияние природных и техногенных факторов на проявление сейсмичности на рудниках Хибинского массива // Триггерные эффекты 
Известия Томского политехнического университета. Инжиниринг георесурсов. 2020. Т. 331. № 2. 45-53

Немова Н.А., Бельш Т.А. Оценка вариантов отработки прибортовых и подкарьерных запасов рудника «Олений ручей»

в геосистемах: тезисы докладов IV Всероссийской конференции с международным участием. - М.: ГЕОС, 2017. C. $46-47$.

24. Kozyrev A.A., Semenova I.E., Zemtsovskiy A.V. Investigation of geomechanical features of the rock mass in mining of two contiguous deposits under tectonic stresses // Procedia
Engineering. - 2017. - V. 191. - P. 324-331. DOI: 10.1016/j.proeng. 2017.05.188.

Поступила: 15.01 .2019 г.

\section{Информация об авторах}

Немова Н.A., кандидат технических наук, старший научный сотрудник лаборатории «Открытые горные работы» Института горного дела им. Н.А. Чинакала Сибирского отделения Российской академии наук.

Бельш T.A., инженер лаборатории «Открытые горные работы», Института горного дела им. Н.А. Чинакала Сибирского отделения Российской академии наук. 
UDC 622.271

\title{
ASSESSMENT OF PIT WALL AND PIT BOTTOM RESERVES WORKING OPTIONS IN THE MINE «OLENIY RUCHEY»
}

\author{
Natalya A. Nemova ${ }^{1}$, \\ nemova-nataly@mail.ru \\ Tatyana A. Belsh1, \\ tata0303@bk.ru \\ 1 Institute of Mining, Siberian Branch, Russian Academy of Sciences, \\ 54, Krasny avenue, Novosibirsk, 630091, Russia.
}

The relevance of the research is caused by the need to develop new ore bodies appeared in the course of advanced operational exploration. Behind the design contours of the mines there are the reserves that need to be improved either by underground or combined methods. With the technology of refining the quarry reserves, the greatest difficulties arise, since their development causes a violation of the stability of the quarry sides. Therefore, the search, selection and justification of the parameters of the systems for developing pre-pit reserves in deposit exploration, providing effective and safe development of reserves, is a very urgent task.

The main aim of the research is to consider possible options for pit mining of the pit wall and pit bottom reserves taking into account the occurrence of new ore bodies of apatitenepheline deposit and compliance with the necessary conditions for a specified direction of mining development of mining boundary of property and to make a technical and economic assessment of the proposed options.

Objects: large deposit of apatite-nepheline ores «Oleniy Ruchey».

Methods: mining and geological analysis of the upper tier of deposits of apatite-nepheline ores "Oleniy Ruchey» and analysis of existing data on the physicomechanical properties of rocks composing the massif of the deposit in question, analysis of possible mining development schemes for mining deposits and reserves with an assessment of the possibility of internal dumping during quarry development.

Results. On the example of development of the deposit of apatite-nepheline ores "Oleniy Ruchey», the authors considered possible options for mining and developing the pit wall and pit bottom reserves of the upper tier deposits in compliance with the conditions of development of mining boundary of property. The authors proposed the optimal development of mining operations according to the variant providing the minimum stripping ratio.

\section{Key words:}

Pit wall and pit bottom reserves, ore body, schemes of opening, completion of reserves, overburden coal ratio, mining position.

\section{REFERENCES}

1. Gavrishev S.E., Kuznetsova T.S., Nekerova T.V. Methods of substantiation of the parameters of the pit walls during the excavation of near-surface reserves by the underground method. Bulletin Magnitogorsk state technical University named G.I. Nosov, 2010, no. 1, pp. 14-17. In Rus.

2. Kalmykov V.N., Grigoryev V.V., Volkov P.V. Explore options for development systems for excavating pit walls reserves in combined geotechnology. Bulletin Magnitogorsk state technical University named G.I. Nosov, 2010, no. 1, pp. 17-20. In Rus.

3. Sakantsev G.G., Sakantsev M.G., Cheskidov V.I., Norri V.K. Improvement of systems of development of deep deposits on the basis of optimization of elements of their opening and parameters of pits. Physical and technical problems of development of mineral deposits, 2014, no. 4, pp. 117-123. In Rus.

4. Cheskidov V. I., Norri V.K., Zaytsev G.D., Botvinnik A.A., Bobylskiy A.S., Reznik A.V. Povyshenie effektivnosti technology otkrytoy razrabotki mestorozhdeny tverdykh poleznykh iskopaemykh [Increasing efficiency of open pit hard mineral mining]. Journal of Mining Science, 2014, vol. 50, no. 5, pp. 892 903.

5. Eremin G.M. Increasing the efficiency of Nyorkpakhsky open-pit mining. Mining information and analytical bulletin (Scientific and Technical Journal), 2012, no. 4, pp. 36-42. In Rus.

6. Belyaev S.I., Eremin G.M. Increasing the completeness of mining ore bodies of Nyorkpakhsky field when using a steeper convex board pit. Mining information and analytical bulletin (Scientific and Technical Journal), 2004, no. 5, pp. 238-242. In Rus.

7. Lobanov E.A., Chaykin D.A., Menshikov P.Yu. Development of technological solutions for the opening and mining of pit bottom and pit wall reserves of apatite-nepheline ores. Fundamental and applied sciences in mining, 2018, vol. 5, no. 1, pp. 88-93. In Rus.
8. Okunovich A.V., Ryzhkov A.N. The importance of the timely adoption of decisions concerning the choice of optimal reserves (for example Nyorkpakhsky deposits of Apatite-nepheline ores). Mining journal, 2010, no. 4, pp. 98-100. In Rus.

9. Kalyuzhny A.S. Determination of the parameters of the disturbed zone and the volumes of potential dumps for the conditions of the Oleniy Ruchey quarry. Mining Information and Analytical Bulletin, 2016, no. 7, pp. 403-412. In Rus.

10. Dowling J., Beale G., Bloom J. Designing a large scale pit slope depressurization system at Bingham canyon. Annual International Mine Water Association Annual Conference. Reliable Mine Water Technology. Denver, Colorado, USA, 2013. Vol. I, pp. 119-125.

11. Tapia A., Contreras L.F., Jefferies M., Steffen O. Risk evaluation of slope failure at the Chuquicamata mine. Slope Stability 2007. Proc. of 2007 International Symposium on Rock Slope Stability in Open Pit Mining and Civil Engineering. Ed. by Y. Potvin. Australian Centre for Geomechanics, Perth, 2007. pp. 477-495.

12. Brummer R.K., Li H., Moss A., Casten T. The Transition from open pit to underground mining: an unusual slope failure mechanism at Palabora. Proc. of international symposium on stability of rock slopes in open pit mining and civil engineering. Johannesburg, The south African institute of mining and metallurgy, 2006. pp. 411-420.

13. Wines D.R., Lilly P.A., Measurement and analysis of rock mass discontinuity spacing and frequency in part of the Fimiston open pit operation in Kalgoorie, Western Australia: a case study. International Journal of Rock Mechanics \& Mining Science, 2002, vol. 39, no. 5, pp. 589-602.

14. Guidelines for open pit slope design. Eds. J. Read, P. Stasey. Translated from English. Ekaterinburg, Pravoved Publ., 2015. $544 \mathrm{p}$.

15. Laubcher D.H. A geomechanics classification system for rating of rock mass in mine design. Journal South Africa Inst. of Mining and Metallurgy, 1990, no. 10, pp. 257-273. 
16. Jacubec J., Laubcher D.H. The MRMR (Mining Rock Mass Rating) rock mass rating classification system in mining practice. Proceedings of MassMin 2000. Brisbane, Australia, 2000. pp. 413421.

17. Laubcher D.H., Jacubec J. The MRMR (Mining Rock Mass Rating) rock mass classification for jointed rock masses. Underground Mining Methods: Engineering Fundamentals and International Case Studies. Littleton, Colorado, USA, Society for Mining, Metallurgy, and Exploration (SME), 2001. pp. 475-481.

18. Haines A., Terbrugge P.J., Wittke W. Preliminary estimation of rock slope stability using rock mass classification systems. Proc. $7^{\text {th }}$ Cong. on Rock Mechanics. ISRM. Aachen, Germany; Balkema, Rotterdam, 1991. pp. 887-892.

19. Otchet o nauchno-issledovatelskoy rabote «Inzhenernogeologicheskie usloviya razrabotki apatitonefelinovogo mestorozhdeniya Oleniy ruchey" [Report on the research work «Engineering and geological conditions for the development of the Oleniy Ruchey apatite-nepheline deposit»]. Apatity, Mining Institute of the Kolskiy Scientific Center Russian Academy of Sciences Publ., 2009. $160 \mathrm{p}$.

20. Otchet o nauchno-issledovatelskoy rabote «Reglament na ukruchenie bortov karera mestorozhdeniya apatit-nefelinovoy rudy Oleniy ruchey» [Report on the research work «Regulations for the tilting of the pit sides of the pit of the Oleniy Ruchey apatitenepheline ore deposit»]. Apatity, Mining Institute of the Kolskiy Scientific Center Russian Academy of Sciences Publ., 2012. 175 p

21. Otchet o nauchno-issledovatelskoy rabote «Opredelenie osnovnykh parametrov fiziko-mekhanicheskikh svoystv gornykh porod po razrezu strukturnoy inzhenerno-geologicheskoy skvazhiny dlya otsenki geomekhanicheskikh usloviy prokhodki glavnogo stvola» [Report on the research work «Determination of the main parameters of the physicomechanical properties of rocks from the section of a structural engineering-geological well for the assessment of the geomechanical conditions of penetration of the main wellbore»]. Apatity, Mining Institute of the Kolskiy Scientific Center Russian Academy of Sciences Publ., 2013. 142 p.

22. Otchet o nauchno-issledovatelskoy rabote «Razrabotka osnovnykh tekhnologicheskikh resheniy (reglamenta) dlya vskrytiya $i$ otrabotki pribortovykh i podkarernykh zapasov verkhnego yarusa mestorozhdeniya Oleniy ruchey» [Report on the research work «Development of the main technological solutions (regulations) for the opening and testing of pit bottom and pit wall reserves of the upper tier of the Oleniy Ruchey deposit»). Novosibirsk, Institute of Mining Siberian Branch Russian Academy of Sciences Publ., 2018. 180 p.

23. Kozyrev A.A., Semenova I.EH., Zhuravleva O.G. Vliyanie prirodnykh i tekhnogennykh faktorov na proyavlenie seysmichnosti na rudnikakh Khibinskogo massiva [The influence of natural and technogenic factors on manifestation of seismicity in the mines of the Khibiny massif]. Triggernye effekty $v$ geosistemakh. Tezisy dokladov IV Vserossiyskoy konferentsii s mezhdunarodnym uchastiem [Trigger effects in geosystems. Abstracts of the IV All-Russian Conference with international participation]. Moscow, GEOS Publ., 2017. pp. 46-47.

24. Kozyrev A.A., Semenova I.E., Zemtsovskiy A.V. Investigation of Geomechanical Features of the Rock Mass in Mining of Two Contiguous Deposits under Tectonic Stresses. Procedia Engineering, 2017, vol. 191, pp. 324-331. DOI: 10.1016/j.proeng.2017.05.188.

Received: 15 January 2019.

\section{Information about the authors}

Natalya A. Nemova, Cand. Sc., senior researcher, Institute of Mining Siberian Branch Russian Academy of Sciences.

Tatyana A. Belsh, engineer, Institute of Mining Siberian Branch Russian Academy of Sciences. 